\title{
Selected Topics on Perspectives in Business Informatics Research: Editorial Introduction to the Issue 14 of CSIMQ
}

\author{
Björn Johansson $^{* 1}$ and Charles Møller ${ }^{2}$ \\ ${ }^{1}$ School of Economics and Management, Lund University, Ole Römers väg 6, \\ SE-223 63 Lund, Sweden \\ ${ }^{2}$ Department of Materials and Production, Aalborg University, Center for Industrial \\ Production, Fibigerstræde 10, 9220 Aalborg, Denmark \\ bjorn.johansson@ics.lu.se, charles@mp.aau.dk
}

Globalization, abundant networking possibilities, and advances in artificial intelligence are creating a new business environment where cooperation and competition requires from enterprises high agility and ability to intelligently acquire, analyze, and apply their internal and external data. In this regard, several information system concepts must be reconsidered to adopt various opportunities offered by the new environment. The fourteenth issue of the journal "Complex Systems Informatics and Modeling Quarterly" (CSIMQ) offers a selection of papers addressing research perspectives that concern digital trade infrastructures, business process agility, and the quality of business intelligence tools. The initial versions of these papers were presented and discussed at the 16th International Conference on Perspectives in Business Informatics Research and its associated events on August 28-30, 2017 in Copenhagen, Denmark.

Digital trade infrastructures are shown as a new concept to compare to global information systems in "Digital Trade Infrastructures: A Framework for Analysis," by Boriana Rukanova, Stefan Henningsson, Helle Zinner Henriksen, and Yao-Hua Tan. Several cases of introduction of digital trade infrastructures are discussed and features of these infrastructures that set them apart to other digital infrastructures are outlined. The authors show that the introduction of digital infrastructures that transcend organizational and system domains is driven by the prospect of reducing the fragmentation of information, thereby enabling improved security and efficiency in the trading process. The article proposes a digital trade infrastructure framework that can be used to analyze and compare other digital trade infrastructures.

Other four articles deal with business process agility and address compatibility issues regarding business process tasks and business intelligence implementations. "Building a Process Driven Organization with the Process Normalization Technique" by Václav Repa shows that the methodological standards for business process modeling are still very much insufficient. The paper addresses one of such insufficiencies, namely, the problems regarding unity of objectoriented and process-oriented views of a business system. To achieve such unity, the article

\footnotetext{
* Corresponding author

(C) 2018 Björn Johansson and Charles Møller. This is an Open Access article licensed under the Creative Commons Attribution License (CC BY 4.0), https://creativecommons.org/licenses/by/4.0

Reference: B. Johansson and C. Møller, "Selected Topics on Perspectives in Business Informatics Research: Editorial Introduction to the Issue 14 of CSIMQ," Complex Systems Informatics and Modeling Quarterly, CSIMQ, no. 14, pp. I-II, 2018. Available: https://doi.org/10.7250/csimq.2018-14.00
}

Additional information. Authors ORCID iD: B. Johansson - orcid.org/0000-0002-3416-4412, C. Møller - orcid.org/0000-00030251-3419. Article PII S225599221800079X. Received: 28 April 2018. Available online: 30 April 2018. 
introduces a process normalization technique. This technique is inspired by the famous 'ancient' Normalization of Data Structures technique which is regarded as relevant and correct because of the essential unity of objects and processes in the business system.

"Effort Estimation in BPMS Migration" by Christopher Drews and Birger Lantow, suggests a framework that identifies basic building blocks for effort estimation in business process management system (BPMS) migration. The article describes how the framework was developed. It demonstrates main artifacts of effort estimation that are based on the framework. The applicability of the framework is discussed on the basis of its use in a particular BPMS migration scenario.

Rikke Gaardboe, Tanja Svarre and Tom Nyvang in their article "The Relationship between Task Characteristics, BI Quality and Task Compatibility: An Explorative Study," show interesting data on how the business intelligence solutions comply to the tasks of their users. The authors have conducted a survey of three companies, where 104 business intelligence end users answered a questionnaire. The main contribution of the survey is a better understanding of how tasks and business intelligence fit together.

In their article "Business Processes Modeling Recommender Systems: User Expectations and Empirical Evidence," Michael Fellmann, Novica Zarvić, and Oliver Thomas apply recommender functionalities to business process modeling and investigate their potential for process modeling. To do so, they have implemented two prototypes, and demonstrated and experimented with them in different settings. Thus they were able to acquire user feedback from demonstrations and compare it with the experimental data. The authors thoroughly discuss the obtained results and hypothesize on two "sweet spots" of process modeling recommender systems.

We hope that the readers will find this selection of papers interesting and useful. We would like to thank all the authors for submitting their papers to CSIMQ as well as CSIMQ Editorial review Board members and external reviewers for providing multiple important comments and suggestions for the authors. 